\title{
BMJ Open Public health measures to reduce the risk of SARS-CoV-2 transmission in Canada during the early days of the COVID-19 pandemic: a scoping review
}

\author{
Julie Polisena (D) , ${ }^{1}$ Maria Ospina, ${ }^{2}$ Omolara Sanni, ${ }^{3}$ Brittany Matenchuk, ${ }^{3}$ \\ Rachel Livergant, ${ }^{3}$ Sana Amjad, ${ }^{3}$ Igor Zoric, ${ }^{3}$ Nisrine Haddad, ${ }^{4}$ Andra Morrison, ${ }^{5}$ \\ Kumanan Wilson, ${ }^{4,6}$ Isaac Bogoch, ${ }^{7}$ Vivian A Welch ${ }^{4,8}$
}

To cite: Polisena J, Ospina M, Sanni 0, et al. Public health measures to reduce the risk of SARS-CoV-2 transmission in Canada during the early days of the COVID-19 pandemic: a scoping review. BMJ Open 2021;11:e046177. doi:10.1136/ bmjopen-2020-046177

- Prepublication history and additional material for this paper are available online. To view these files, please visit the journal online (http://dx.doi. org/10.1136/bmjopen-2020046177).

$\mathrm{JP}$ and $\mathrm{M} 0$ are joint senior authors.

Received 22 October 2020 Revised 30 January 2021 Accepted 03 February 2021

Check for updates

(c) Author(s) (or their employer(s)) 2021. Re-use permitted under CC BY-NC. No commercial re-use. See rights and permissions. Published by BMJ.

For numbered affiliations see end of article.

Correspondence to Dr Julie Polisena; jpolis22@hotmail.com

\section{ABSTRACT}

Objective The main objectives of this study were to synthesise and compare pandemic preparedness strategies issued by the federal and provincial/territorial $(\mathrm{P} / \mathrm{T})$ governments in Canada and to assess whether COVID-19 public health $(\mathrm{PH})$ measures were tailored towards priority populations, as defined by relevant social determinants of health.

Methods This scoping review searched federal and $\mathrm{P} / \mathrm{T}$ websites on daily COVID-19 pandemic preparedness strategies between 30 January and 30 April 2020. The PROGRESS-Plus equity-lens framework was used to define priority populations. All definitions, policies and guidelines of $\mathrm{PH}$ strategies implemented by the federal and $\mathrm{P} / \mathrm{T}$ governments to reduce risk of SARS-CoV-2 transmission were included. PH measures were classified using a modified Public Health Agency of Canada Framework for Canadian Pandemic Influenza Preparedness.

Results A total of 722 COVID-19 PH measures were issued during the study period. Of these, home quarantine (voluntary) ( $n=13.0 \% ; 94 / 722)$ and retail/commerce restrictions $(10.9 \% ; n=79 / 722)$ were the most common measures introduced. Many of the PH orders, including physical distancing, cancellation of mass gatherings, school closures or retail/commerce restrictions began to be introduced after 11 March 2020. Lifting of some of the $\mathrm{PH}$ orders in phases to reopen the economy began in April $2020(6.5 \% ; n=47 / 722)$. The majority $(68 \%, n=491 / 722)$ of COVID-19 PH announcements were deemed mandatory, while $32 \%$ ( $n=231 / 722)$ were recommendations. Several $\mathrm{PH}$ measures $(28.0 \%, \mathrm{n}=202 / 722)$ targeted a variety of groups at risk of socially produced health inequalities, such as age, religion, occupation and migration status. Conclusions Most PH measures centred on limiting contact between people who were not from the same household. PH measures were evolutionary in nature, reflecting new evidence that emerged throughout the pandemic. Although $\sim 30 \%$ of all implemented COVID-19 $\mathrm{PH}$ measures were tailored towards priority groups, there were still unintended consequences on these populations.

\section{INTRODUCTION}

In December 2019, a novel coronavirus was first identified among a cluster of
Strengths and limitations of this study

- Our study presents a comprehensive synthesis of the public health $(\mathrm{PH})$ communication and outreach measures the federal and provincial/territorial $(\mathrm{P} / \mathrm{T})$ governments issued in the first 90 days of the COVID-19 pandemic.

- The results provide important insights on the categories, volume, timing, level of implementation and consideration of equity issues of the $\mathrm{PH}$ measures issued by federal and $\mathrm{P} / \mathrm{T}$ jurisdiction.

- The timeframe for the study precludes us from identifying possible long-term trends on the $\mathrm{PH}$ measures implemented during the 90-day period and their potential impact on priority populations.

- It is possible that PH measures announced only through media releases may have been missed, but most announcements would have been issued by the government press releases.

pneumonia cases in Wuhan City, Hubei Province, China. The virus was named SARS-CoV-2 and represents the causative agent of a potentially fatal infectious disease known as COVID-19. ${ }^{1}$ The severity ranges from mild to severe illness or death for confirmed COVID-19 cases. $^{2}$

On 30 January 2020, the WHO declared the COVID-19 epidemic a global health emergency, and by 11 March 2020 declared COVID-19 a global pandemic. The reproduction numbers $\left(\mathrm{R}_{0}\right)$ of the infectious disease were estimated to be between 2.24 and 3.58 in the early phases of the outbreak in mainland China, resulting in the exponential growth and subsequent spread of the virus across the world. ${ }^{3}$ As of 26 January 2021, the Public Health Agency of Canada (PHAC) reported 757022 confirmed cases and 19403 deaths within Canada, with large variations across jurisdictions. ${ }^{4}$ 
Canada is a high-income country located in North America with a population of approximately 37.9 million. ${ }^{5}$ The country is divided into 10 provinces and 3 territories. In Canada, the federal government is responsible for administering the national principles under the Canada Health Act, which are criteria and conditions for health insurance plans that the provinces and territories must meet so they can receive federal cash transfers. The Canadian government provides financial support to provincial and territorial $(\mathrm{P} / \mathrm{T})$ governments to aid in the delivery of programmes and services, including healthcare. The provinces and territories therefore administer and deliver most of Canada's healthcare services within their jurisdiction. Healthcare decision-making and priority settings in the healthcare system are decentralised and occur at various levels, including regional and local.

In response to the COVID-19 pandemic, Canadian public health $(\mathrm{PH})$ officials at all levels of administration issued response interventions to contain and mitigate SARS-CoV-2 transmission at a population level and prepare the health systems' response to the infectious disease. The definitions and scope of these PH measures vary by federal and $\mathrm{P} / \mathrm{T}$ governments in their characteristics, target populations, time of initiation in the pandemic curve and duration of implementation since they may change over time in response to the dynamics in the epidemic curve. ${ }^{6}$ Different strategies, however, may be warranted in response to growth curves or other triggers.

The pandemic situation unveiled persisting health inequalities rooted in multiple, structural and intersecting determinants of the conditions in which people live-particularly increasing the vulnerability of the most socially and economically disadvantaged groups. ${ }^{7-9}$ As the COVID-19 pandemic continues to unfold, it is important to understand which measures work under specific circumstances. We must also expand our knowledge about the potential impact of these population-level mitigation and containment strategies on priority populations rooted in well-known social, economic and structural determinants of health. Racism and discrimination, income, education, occupation, gender and others are such determinants. ${ }^{10}$ Results from this work can help to inform equitable, effective and coordinated responses to future pandemics across Canada and in other jurisdictions in the design and planning of strategies to mitigate negative impacts and maximise positive impacts of $\mathrm{PH}$ measures.

Our study objectives were twofold: (1) to identify and systematically describe and compare the $\mathrm{PH}$ pandemic preparedness strategies for COVID-19 issued by the Canadian federal and $\mathrm{P} / \mathrm{T}$ governments; and (2) to assess whether COVID-19 PH measures were tailored towards priority populations, as defined by relevant social determinants of health in Canada.

\section{METHODS}

\section{Search strategy and eligibility criteria}

We conducted a scoping review of COVID-19 PH measures adopted across Canadian provinces and territories. ${ }^{11}$ The search strategy consisted of daily hand searching of information on COVID-19 PH preparedness strategies released on federal and $\mathrm{P} / \mathrm{T}$ websites on a daily basis between 30 January and 30 April 2020 (online supplemental file 1). For our study, electronic searches of the scientific literature were not conducted. The selection criteria of evidence included definitions, policies and guidelines of $\mathrm{PH}$ strategies implemented by the federal and $\mathrm{P} / \mathrm{T}$ governments to reduce the risk of SARS-CoV-2 transmission and prepare the communities for the COVID-19 pandemic. $\mathrm{PH}$ measures issued at the regional or municipal level were not included. Federal and $\mathrm{P} / \mathrm{T}$ financial plans to individuals, families or businesses during the COVID-19 pandemic were also excluded. Additional details on eligibility criteria are outlined in table 1 .

\section{Data abstraction and synthesis of results}

We used the PHAC framework for Canadian Pandemic Influenza Preparedness to classify all PH measures identified in the search strategy. ${ }^{12}$ We also incorporated additional measures not included in the PHAC framework, such as contact tracing and testing. COVID-19 PH measures were characterised by level of implementation

\begin{tabular}{ll}
\hline Table 1 Eligibility criteria \\
\hline Criterion & Description \\
\hline Population & General population in Canada, including paediatrics and adults. \\
Intervention & Recommendations, policy, guidance, guiding principles or guidelines that describe PH measures to contain \\
& $\begin{array}{l}\text { and/or mitigate the risk of transmission of COVID-19 in Canada. PH measures were categorised according to } \\
\text { the PHAC framework for Canadian Pandemic Influenza Preparedness measures. }\end{array}$ \\
& Examples of PH measures may include social or physical distancing measures; self-isolation; quarantines; \\
& school, university or daycare closures; working from home; limited visitation hours in healthcare or long-term \\
& facilities; or travel restrictions and bans.
\end{tabular}

$\mathrm{PH}$, public health; PHAC, Public Health Agency of Canada. 
(ie, mandatory or recommended), timing (ie, date) of implementation and target populations.

Priority populations in this scoping review were defined as population groups at risk of socially produced health inequities. ${ }^{13}$ We used the PROGRESS-Plus equity-lens framework to classify these populations according to the following social determinants of health: place of residence; race/ethnicity/culture/language (including Indigenous identities); occupation/employment/working conditions; gender and sex; religion background; education; socioeconomic status (eg, income, housing, single-parent family, food and home security); and social capital and networks (eg, neighbourhood characteristics, community supports). The Plus refers to other characteristics potentially associated with discrimination: age groups, immigration status and disability. ${ }^{13}$

One reviewer extracted data from press releases on the government websites for their assigned jurisdiction(s), and a second reviewer checked for the accuracy of the extracted data. As well, a reviewer compared our data with the results of the COVID-19 Intervention Scan conducted by the Canadian Institutes for Health Information (CIHI) to verify that no $\mathrm{PH}$ measures were omitted. ${ }^{14}$ Online supplemental file 2 lists the individual data elements that were extracted for all COVID-19 PH measures issued across Canadian jurisdictions between 30 January and 30 April 2020.

PH measures were classified according to two major categories: PH communication and education (eg, communication campaigns to maintain social distancing) and $\mathrm{PH}$ orders (eg, prohibition on mass gatherings in excess of 50 people). Similarly, COVID-19 PH measures were described by their time of publication and target audience. Information about COVID-19 PH measures and priority populations identified in the scoping review were narratively synthesised and tabulated.

\section{Ethics approval}

As the information used in our scoping review was derived from public data sources, a formal ethics approval was not required.

\section{Role of the funding source}

The study sponsor(s) did not have any involvement in study design, data collection, analysis, interpretation of data, writing of the report or in the decision to submit the paper for publication.

\section{Patient and public involvement}

As our study used secondary data sources, patients and the public were not involved in our scoping review.

\section{RESULTS}

The scoping review identified a total of $722 \mathrm{PH}$ measures issued by federal and $\mathrm{P} / \mathrm{T}$ governments between 30 January and 30 April 2020.
Public health communication and education

All federal and $\mathrm{P} / \mathrm{T}$ jurisdictions $(\mathrm{n}=14)$ issued individual PH measures (20.6\% of all measures) between 30 January and 30 April with respect to home quarantine (voluntary) $(\mathrm{n}=14 / 14)$, followed by self-isolation (voluntary) $(\mathrm{n}=13 / 14)$ (table 2). These measures targeted individuals who experienced COVID-19 symptoms or had returned from domestic or international travel. Fewer jurisdictions communicated measures specific to, or solely focused on, environmental cleaning (home/personal environment) $(n=3 / 14)$ or respiratory etiquette $(7 / 14)$. Home quarantine (voluntary) $(\mathrm{n}=13.0 \%$; 94/722) was the most common $\mathrm{PH}$ measure issued by the federal and $\mathrm{P} / \mathrm{T}$ governments that targeted COVID-19 spread at the individual level.

\section{Public health orders}

PH orders on physical distancing measures $(n=13 / 14)$, border and travel measures $(n=13 / 14)$, healthcare settings $(n=13 / 14)$, and childcare or school closures $(n=13 / 14)$ were common across jurisdictions. Announcements related to environmental cleaning (public spaces) $(\mathrm{n}=12 / 14)$, assisted living facilities (eg, group homes, private and public long-term care facilities, private and public senior residences, shelters) $(n=12 / 14)$, cancellations of mass gatherings $(n=12 / 14)$, and case contact or tracing management measures $(n=12 / 14)$ were also relatively common. Fewer jurisdictions explicitly addressed community/faith-based organisations (eg, restrictions or cancellations) $(\mathrm{n}=8 / 14)$ or workplace functioning (eg, workspace restrictions, remote work) $(n=9 / 14)$. Manitoba and the Yukon were the sole jurisdictions to release a PH measure related to remote and isolated communities. Many mandatory PH measures announced by the federal government centred on international border and travel restrictions given their authority to issue them. The most common PH orders issued across Canada centred on retail/commerce restrictions (10.9\%; $n=79 / 722)$, closely followed by border and travel measures, including both international and interprovincial travel (10.8\%; $\mathrm{n}=78 / 722)$.

\section{Time of publication}

Several jurisdictions made communication and education announcements in late January on individual measures. For instance, Quebec issued a PH measure on hand hygiene respiratory etiquette on 30 January 2020. Most $\mathrm{PH}$ communication and education measures on hand hygiene, voluntary self-isolation and voluntary home quarantine were issued in March 2020 across numerous jurisdictions (table 2). Communication on the use of masks was initiated in April 2020 across the $\mathrm{P} / \mathrm{T}$ jurisdictions.

Many of the PH orders, such as physical distancing, cancellation of mass gatherings, school closures and retail/commerce restrictions, were introduced after 11 March 2020. Lifting of some of the PH orders in phases to reopen the economy began in April 2020 (6.5\%; $\mathrm{n}=47 / 722)$. 


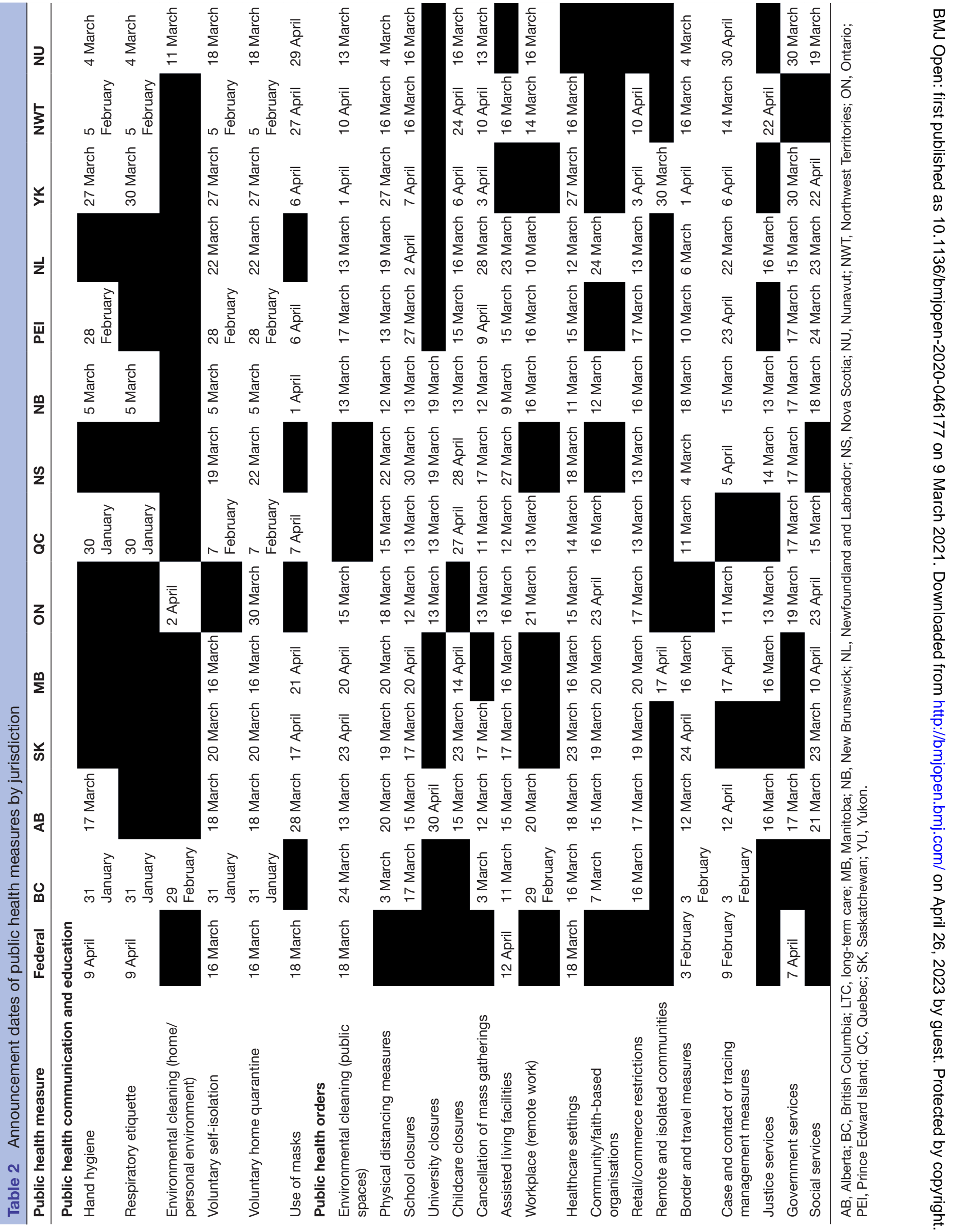




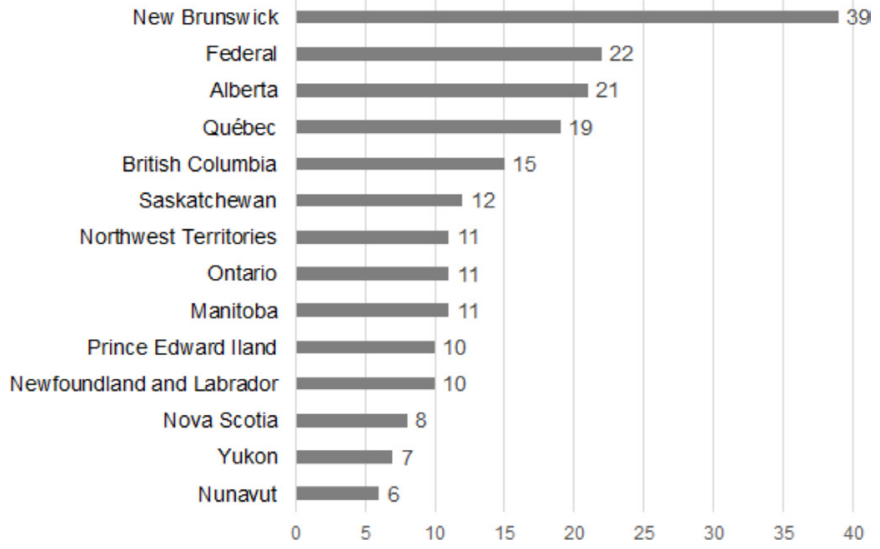

Figure 1 Individual public health measures that scoped priority populations across jurisdictions: number of public health measures issued that target priority populations.

\section{Level of intervention}

Based on the language used in the press releases, $68 \%$ $(\mathrm{n}=491)$ of the COVID-19 PH announcements were deemed as mandatory, while $32 \%(n=231)$ were recommendations. Although many of the measures classified as $\mathrm{PH}$ communication and education were determined to be recommendations by governments, measures related to voluntary self-isolation and home quarantine were primarily mandatory (online supplemental file 3).

The majority of PH orders that focused on cancellation of mass gatherings, school closures and assisted living facilities were mandatory. While numerous border and travel measures and retail/commerce restrictions were considered mandatory, several related measures were recommendations.

\section{Target population}

The general public was the target for $68 \%(n=490 / 722)$ of the issued COVID-19 PH measures. Other targets included children aged $<17$ years $(8.4 \%, \mathrm{n}=61 / 722)$, healthcare provider groups $(7.1 \%, \mathrm{n}=51 / 722)$, individuals aged $>65$ years $(5.0 \%, \mathrm{n}=35 / 722)$ and those with physical disabilities $(4.4 \%, \mathrm{n}=32 / 722)$ and mental health problems $(1.1 \%, \mathrm{n}=8 / 722)$.

\section{Public health measures tailored towards priority populations}

Of the $722 \mathrm{PH}$ measures identified in the scoping review, $28.0 \%(n=202 / 722)$ were tailored to priority populations. Figure 1 shows the distribution of $\mathrm{PH}$ measures that scoped priority populations across jurisdictions. The $\mathrm{PH}$ measures targeted a variety of groups defined by major social determinants of health (figure 2). Of all $722 \mathrm{PH}$ measures, $13.4 \%(n=97 / 722)$ were tailored to groups defined by age, while COVID-19 PH measures were less frequently tailored towards groups based on occupation $(5.7 \%, \mathrm{n}=41 / 722)$ or migration status $(3.7 \%, \mathrm{n}=27 / 722)$. Other priority groups less frequently targeted included those defined by income and home security conditions $(1.5 \%, \mathrm{n}=11 / 722)$; religious background $(1.4 \%$, $\mathrm{n}=10 / 722)$; race, ethnicity and/or language groups (1.0\%, $\mathrm{n}=7 / 722)$, including Indigenous populations

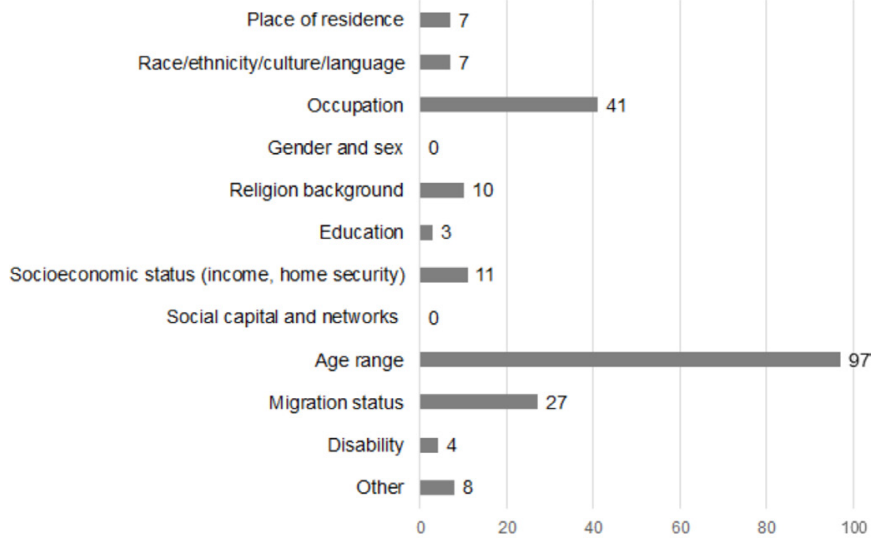

Figure 2 Priority populations target by COVID-19 public health measures in Canada: number of public health measures issued for each priority population identified.

$(0.7 \%, \mathrm{n}=5 / 722)$; and individuals with disabilities $(0.5 \%$, $\mathrm{n}=4 / 722)$. Other COVID-19 PH measures targeted 'vulnerable' populations that were not further defined $(1.1 \%, \mathrm{n}=8 / 722)$. None of the measures targeted populations defined by sex and gender.

\section{DISCUSSION}

Our scoping review is a descriptive study, so a quantitative assessment of the impact of PH measures was outside the scope. Furthermore, our objective was to identify, describe, classify and compare the experiences in implementing $\mathrm{PH}$ measures at the national and $\mathrm{P} / \mathrm{T}$ levels during the early stages of the pandemic. The results present a comprehensive synthesis of the $\mathrm{PH}$ communication, outreach activities and $\mathrm{PH}$ orders in Canada by jurisdiction. They also provide insights on the categories, volume, timing, level of implementation and consideration in equity issues of the $\mathrm{PH}$ measures issued by the federal and $\mathrm{P} / \mathrm{T}$ governments.

This scoping review identified a total of $722 \mathrm{PH}$ measures that were implemented by federal and $\mathrm{P} / \mathrm{T}$ governments across Canada during the first 90 days of the COVID-19 pandemic. These measures were implemented to slow the growth rate of infections and to reduce the risk of an overburdened healthcare system. ${ }^{15}$ The study results showed that many of the measures focused on home quarantine (voluntary) and retail/commerce restrictions, targeted towards the general public.

From an equity-based perspective, approximately onethird of all COVID-19 PH measures implemented in federal and $\mathrm{P} / \mathrm{T}$ jurisdictions were specifically tailored towards priority groups as defined by the social determinants of health. ${ }^{1617}$ None of the PH measures specifically targeted sex and gender (figure 2), but some of the $\mathrm{PH}$ measures in place, such as school closures, disproportionately affected women both at home and in the workplace. ${ }^{18}$ Although social capital and networks impact the spread of COVID-19, our review did not identify any $\mathrm{PH}$ measures issued in the early days of the pandemic that 
targeted this domain. ${ }^{19}$ Other PH measures focused on restrictions of large gatherings for targeted groups or in specific locations. For instance, $\mathrm{PH}$ measures targeting religious groups centred on prohibiting large gatherings through closures of places of worship or cancellations of religious festivities.

Similar to our scoping review, the results of a descriptive study on non-pharmaceutical interventions (NPIs) implemented in Canada reported that jurisdictions issued many of their PH measures after 11 March 2020. ${ }^{6}$ This date coincides with the WHO's pandemic declaration. The authors also observed some consistency with Europe and Asia in the order of NPI implementation, and less variation across Canada in the implementation of NPIs compared with the USA. ${ }^{6}$

As new evidence on preventive measures emerged for this novel coronavirus, recommendations on the use of face masks were revised from limiting their use to frontline healthcare worker, symptomatic individuals and caregivers to include the general public. ${ }^{20}$ This observation is evident in table 2, where initial communication on face mask use began in April in many jurisdictions. Our findings indicate that geography also influenced the timing of the introduction of the PH measures. As the first outbreak of COVID-19 was reported in China, British Columbia, which borders the Pacific Ocean, issued measures that restricted large gatherings or travel in early February or March. British Columbia was the first province to introduce contact tracing measures on 3 March, while the other Canadian jurisdictions issued similar measures later in March or as late as 30 April. In addition, the data support the idea that the virus is highly contagious and thrives on close interactions in enclosed spaces where physical distancing is not feasible. As such, $\mathrm{PH}$ orders that influenced human behaviours outside the individual's personal environment were issued mostly in March across Canada, and thus, targeted lowering risk of exposure. Finally, the timing of the $\mathrm{PH}$ measures plays an important role in curbing the spread of the virus. For instance, questions have been raised as to whether Canada could have acted sooner in closing its international borders to nonessential travel. This delay may have resulted in missed opportunities to curb viral spread during the earlier days of the pandemic. ${ }^{21}$

Obtaining real-time epidemiological data about the number of individuals who have the disease, and their demographic and clinical characteristics, including age, sex, ethnicity and comorbidities remains a priority. To help address this gap, CIHI proposed an interim ethnicity-based data collection standard to help harmonise and facilitate quality data collection. ${ }^{22}$ In contrast to uniform PH measures, this data system can provide insights on necessary measures customised to incorporate social and economic inequities among priority populations, helping to effectively lower their risk of infection and disease severity. ${ }^{23}$ Moreover, this data system can help inform ineffective measures in mitigating or containing the novel coronavirus, in order to revise future policies accordingly. ${ }^{24}$ This approach is particularly crucial in light of the growing body of evidence on how lockdown measures and the closing of essential businesses have disproportionally affected low income and other vulnerable groups. ${ }^{25}$

PH communication and education (eg, physical distancing, hand hygiene and use of masks) as well as other augmented PH orders (ie, case and contact management or tracing management) that were in place in the early stages of the pandemic to slow the virus transmission must continue to be part of the strategy to lifting restrictions (eg, reopening of businesses and restaurants). Some improvements in testing and contact tracing were observed, as well as increased availability of personal protective equipment in Canada since the beginning of the pandemic. ${ }^{26}$ In addition to self-isolation and support, increased testing capacity and faster turnaround times of test results coupled with sufficient resources for efficient and timely contact tracing are necessary to closely monitor the virus transmission and take appropriate actions to contain the spread. ${ }^{27}$ Although outbreaks will continue to occur, they need not necessarily lead to full lockdown measures, such as those issued in March $2020 .{ }^{26}$ Overall, the adherence and investment in the fundamental pillars of epidemic response are essential to keeping COVID-19 at bay. ${ }^{27}$

Inequalities are a long-standing challenge that have been documented during the current COVID-19 pandemic and other health crises in the past. ${ }^{28}{ }^{29} \mathrm{An}$ increasing body of evidence is emerging in relation to the unequal impacts of the COVID-19 pandemic on infection and mortality rates towards priority groups defined by social determinants of health. ${ }^{89}$ While the role of social inequalities in the dynamics of the COVID-19 pandemic remains to be elucidated, future $\mathrm{PH}$ measures should explicitly and consistently adopt an equity-lens to promote intersectional and multifaceted strategies for pandemic preparedness and response actions that prioritise the needs of vulnerable groups.

\section{Limitations}

Our study timeframe precludes us from identifying possible long-term trends on the $\mathrm{PH}$ measures implemented during the 90-day period and their potential impact on priority populations. It is possible that $\mathrm{PH}$ measures announced only through the media may have been missed in our study. Most announcements, however, would have been issued by the government press releases. As the majority of the identified $\mathrm{PH}$ measures issued by the federal or $\mathrm{P} / \mathrm{T}$ governments did not seem to target priority populations, the authors acknowledge that PH orders at the regional or municipal levels may have addressed these gaps. The authors also recognise that PH measures issued at the municipal level are important contributions to contain and mitigate COVID-19 transmission since they have the ability to police social distancing or bans of mass gatherings and mobilise community centres for quarantine orders and homeless populations. 
The volume of measures collectively provided by the municipalities, however, precluded us from collecting data and gathering information at the local level in the specified timeframe. Moreover, our scoping review did not assess enforcement measures, strategies to adhere to the mandatory PH orders, or if sick leave benefits for stay-at-home orders among individuals in quarantine that were in place in the early stages of the pandemic; thus, further investigation is merited.

\section{Directions for future research}

The results of our scoping review can be used to compare Canada's initial response to the pandemic with the PH measures issued in other countries during the same period. Due to the novelty of the virus, data continue to be collected and verified. A better understanding of the transmission dynamics is important for the planning, development and evaluation of effective control policies. ${ }^{30}$ As such, a comparative analysis on the evolution of the COVID-19 PH orders within Canada compared with other countries as the pandemic progresses is warranted. Once the data on the number of hospitalisations, admissions to the intensive care unit and mortality rates become available for research purposes, an investigation on epidemiological indicators of COVID-19 before and after the implementation of PH measures by jurisdiction would complement the findings in our study. A focus on intended and unintended consequences for priority populations of these $\mathrm{PH}$ measures over a longer period merits additional research. For instance, school closures and work from home measures were intended to help reduce the spread of the virus, but these prolonged measures have also resulted in social isolation and increased mental health morbidities in households.

\section{CONCLUSIONS}

In the absence of an effective treatment or vaccine for SARS-CoV-2 during the early phase of the pandemic, the federal and $\mathrm{P} / \mathrm{T}$ governments relied on the introduction of $\mathrm{PH}$ measures to mitigate the adverse effects of COVID-19. Our findings indicate that PH measures were influenced, in part, by the availability of the evolving evidence, geographical location of the jurisdiction and the aim to modify human behaviours outside an individual's personal environment. While most PH measures centred on limiting contact between people who are not living in the same household, they were also reflective of new evidence on preventive measures emerging in the earlier phase of the pandemic - as highlighted by direction on mask use. Although nearly one-third of all implemented COVID-19 PH measures were tailored towards priority groups, none were specific to sex and gender or social capital and networks. However, several of the $\mathrm{PH}$ measures issued would have resulted in unintended consequences for these populations, such as deterioration in mental health. While the role of social inequalities in the COVID-19 pandemic remains to be elucidated, future PH measures should adopt an equity-lens as data continues to be collected that prioritises the needs of priority populations.

\section{Author affiliations}

${ }^{1}$ Health Technology Assessment Division, International Federation for Medical and Biological Engineering, Ottawa, Ontario, Canada

${ }^{2}$ Faculty of Medicine \& Dentistry, University of Alberta, Edmonton, Alberta, Canada ${ }^{3}$ School of Public Health, University of Alberta, Edmonton, Alberta, Canada ${ }^{4}$ School of Epidemiology and Public Health, University of Ottawa, Ottawa, Ontario, Canada

${ }^{5}$ Canadian Agency for Drugs and Technologies in Health, Ottawa, Ontario, Canada

${ }^{6}$ Clinical Epidemiology Program, Ottawa Hospital Research Institute, Ottawa, Ontario, Canada

${ }^{7}$ Divisions of General Internal Medicine and Infectious Diseases and Department of Medicine, University Health Network, Toronto, Ontario, Canada

${ }^{8}$ Centre for Global Health, Bruyere Research Institute, Ottawa, Ontario, Canada

\section{Twitter Maria 0spina @MariaB0spina}

Acknowledgements The coauthors would like to acknowledge Ms Liz Dennett for her support in identifying the information sources to complete the scoping review.

Contributors JP, MO, VAW, IB and KW contributed to the design and conceptualisation of the scoping review. OS, BM, RL, SA, IZ, NH and AM conducted the data extraction. JP and MO performed the statistical analysis and descriptive synthesis of the results. All authors contributed to the interpretation of data. JP and MO drafted the manuscript and all authors provided critical revisions and contributed to editing of the paper.

Funding This research was funded by the Lois Hole Hospital for Women through the Women and Children's Health Research Institute Start Up Grant (Dr Ospina). Dr Ospina is supported by the Canadian Institutes of Health Research as a Canada Research Chair in Life Course, Social Environments and Health through the Government of Canada.

Competing interests None declared.

Patient consent for publication Not required.

Provenance and peer review Not commissioned; externally peer reviewed.

Data availability statement Data are available upon reasonable request. Requests for data can be submitted to Dr Julie Polisena (ORCID: 0000-0002-1560-3651).

Supplemental material This content has been supplied by the author(s). It has not been vetted by BMJ Publishing Group Limited (BMJ) and may not have been peer-reviewed. Any opinions or recommendations discussed are solely those of the author(s) and are not endorsed by BMJ. BMJ disclaims all liability and responsibility arising from any reliance placed on the content. Where the content includes any translated material, BMJ does not warrant the accuracy and reliability of the translations (including but not limited to local regulations, clinical guidelines, terminology, drug names and drug dosages), and is not responsible for any error and/or omissions arising from translation and adaptation or otherwise.

Open access This is an open access article distributed in accordance with the Creative Commons Attribution Non Commercial (CC BY-NC 4.0) license, which permits others to distribute, remix, adapt, build upon this work non-commercially, and license their derivative works on different terms, provided the original work is properly cited, appropriate credit is given, any changes made indicated, and the use is non-commercial. See: http://creativecommons.org/licenses/by-nc/4.0/.

ORCID iD

Julie Polisena http://orcid.org/0000-0002-1560-3651

\section{REFERENCES}

1 Sun P, Lu X, Xu C, et al. Understanding of COVID-19 based on current evidence. J Med Virol 2020;92:548-51.

2 Wang W, Tang J, Wei F. Updated understanding of the outbreak of 2019 novel coronavirus (2019-nCoV) in Wuhan, China. J Med Virol 2020;92:441-7.

3 Zhao S, Lin Q, Ran J, et al. Preliminary estimation of the basic reproduction number of novel coronavirus (2019-nCoV) in China, from 2019 to 2020: a data-driven analysis in the early phase of the outbreak. Int J Infect Dis 2020;92:214-7. 
4 Public Health Agency of Canada. Coronavirus disease (COVID-19) outbreak. Available: https://www.canada.ca/en/public-health/ services/diseases/2019-novel-coronavirus-infection.html\#a1 [Accessed 23 Jan 2021].

5 Statistics Canada. Population and demography statistics, 2020. Available: https://www.statcan.gc.ca/eng/subjects-start/population and_demography [Accessed 4 Sep 2020].

6 McCoy LG, Smith J, Anchuri K, et al. Characterizing early Canadian federal, provincial, territorial and municipal nonpharmaceutical interventions in response to COVID-19: a descriptive analysis. CMAJ Open 2020;8:E545-53.

7 Dorn Avan, Cooney RE, Sabin ML. COVID-19 exacerbating inequalities in the US. Lancet 2020;395:1243-4.

8 Patel JA, Nielsen FBH, Badiani AA, et al. Poverty, inequality and COVID-19: the forgotten vulnerable. Public Health 2020;183:110-1.

9 The Lancet . Redefining vulnerability in the era of COVID-19. Lancet 2020;395:1089.

10 Wang Z, Tang K. Combating COVID-19: health equity matters. Nat Med 2020;26:458.

11 Arksey H, O'Malley L. Scoping studies: towards a methodological framework. Int J Soc Res Methodol 2005;8:19-32.

12 Public Health Agency of Canada. Public health measures: Canadian pandemic influenza preparedness: planning guidance for the health sector, 2019. Available: https://www.canada.ca/en/public-health/ services/flu-influenza/canadian-pandemic-influenza-preparednessplanning-guidance-health-sector/public-health-measures.html\#appa [Accessed 26 Mar 2020].

13 O'Neill J, Tabish H, Welch V, et al. Applying an equity lens to interventions: using progress ensures consideration of socially stratifying factors to illuminate inequities in health. J Clin Epidemiol 2014;67:56-64.

14 Canadian Institutes for Health Information. COVID-19 intervention scan, 2020. Available: https://www.cihi.ca/en/covid-19-interventionscan [Accessed 25 May 2020].

15 Hartley DM, Perencevich EN. Public health interventions for COVID-19: emerging evidence and implications for an evolving public health crisis. JAMA 2020;323:1908-1909.

16 Ahmed F, Ahmed Na'eem, Pissarides C, et al. Why inequality could spread COVID-19. Lancet Public Health 2020;5:e240.

17 Abrams EM, Szefler SJ. COVID-19 and the impact of social determinants of health. Lancet Respir Med 2020;8:659-61.
18 Connor J, Madhavan S, Mokashi M, et al. Health risks and outcomes that disproportionately affect women during the Covid-19 pandemic: a review. Soc Sci Med 2020;266:113364.

19 Elgar FJ, Stefaniak A, Wohl MJA. The trouble with trust: time-series analysis of social capital, income inequality, and COVID-19 deaths in 84 countries. Soc Sci Med 2020;263:113365.

20 Esposito S, Principi N, Leung CC, et al. Universal use of face masks for success against COVID-19: evidence and implications for prevention policies. Eur Respir J 2020;55:2001260.

21 Dyer E. COVID-19 taught Canada a costly lesson-that early border closures can work, 2020. Available: https://www.cbc.ca/news/ politics/covid-coronavirus-pandemic-trudeau-borders-1.5619705 [Accessed 20 Aug 2020].

22 Canadian Institute for Health Information. CIHI update. Race-based data collection and health reporting, 2020. Available: https://www. cihi.ca/sites/default/files/document/race-standard-reporting-updateen.pdf [Accessed 10 Jun 2020].

23 Douglas M, Katikireddi SV, Taulbut M, et al. Mitigating the wider health effects of covid-19 pandemic response. BMJ 2020;369:m1557.

24 Detsky AS, Bogoch II. COVID-19 in Canada: experience and response. JAMA 2020;324:743-4.

25 Bonaccorsi G, Pierri F, Cinelli M, et al. Economic and social consequences of human mobility restrictions under COVID-19. Proc Natl Acad Sci U S A 2020;117:15530-5.

26 D'Amore R. A second coronavirus lockdown in Canada? experts discuss the likelihood, 2020. Available: https:/globalnews.ca/news/ 7311511/coronavirus-canada-second-lockdown/

27 Fisher DA, Carson G, GOARN Steering Committee. Back to basics: the outbreak response pillars. Lancet 2020;396:598.

28 Bambra C, Riordan R, Ford J, et al. The COVID-19 pandemic and health inequalities. J Epidemiol Community Health 2020;121:jech2020-214401.

29 Quinn SC, Kumar S. Health inequalities and infectious disease epidemics: a challenge for global health security. Biosecur Bioterror 2014;12:263-73.

30 Frieden TR, Lee CT. Identifying and interrupting Superspreading Events-Implications for control of severe acute respiratory syndrome coronavirus 2. Emerg Infect Dis 2020;26:1059-66. 